\title{
Dunning-Kruger Effect, Stages of Competence, and the Need for Endoscopy Training
}

Dunning and Kruger in the year 1999 published their landmark paper describing their hypothesis based on a psychological phenomenon of illusory superiority as a cognitive bias, describing the correlation between ability or competence and ability to objectively analyze one's own ability or competence. This bias leads to people of low ability not being able to objectively analyze their lack of ability due to a lack of metacognition and overestimation of ones' capability. ${ }^{[1]}$ This flawed perception has often been described as the anosognosia of everyday life. People who do not know the right answer to a question often do not have the skill to recognize what the right answer is. ${ }^{[2]}$ For the acquisition of any skill, a person has to go through the four stages of competence which include unconscious incompetence, conscious incompetence, conscious competence, and unconscious competence [Figure 1]..$^{[3]}$ All endoscopists go through these phases of achieving competence with each procedure, whether it is diagnostic endoscopy or advanced therapeutic endoscopy, over a period.

The American Society of Gastrointestinal (GI) Endoscopy has guidelines for privileging, credentialing, and proctoring endoscopies with numbers being defined to achieve competence in each procedure, be it diagnostic and therapeutic upper GI endoscopy and colonoscopy, endoscopic retrograde cholangiopancreatography (ERCP), endoscopic ultrasound (EUS), and enteral stenting [Table 1]. ${ }^{[4]}$ These numbers although not arbitrary give a guideline to mentors for training young endoscopists. There is a steep learning curve for endoscopic interventions such as ERCP and diagnostic and interventional EUS. Since both these procedures are costly, entail high risk of complications, and can be a major source of litigation,

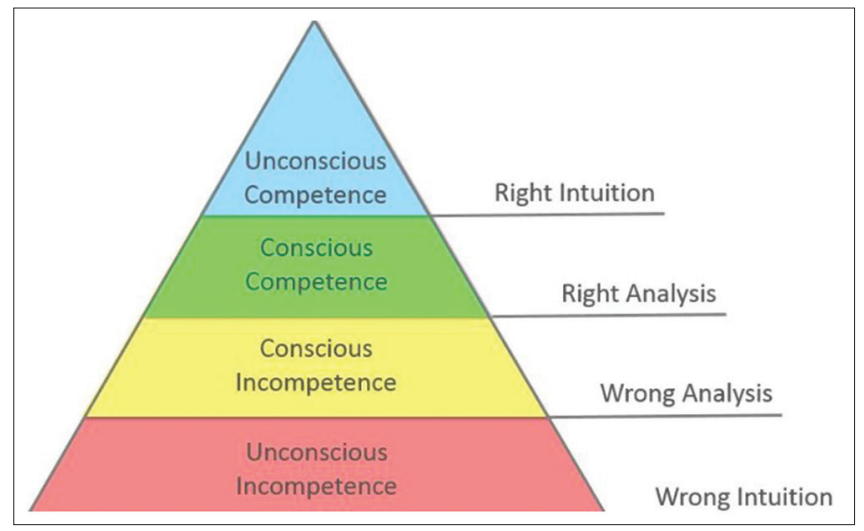

Figure 1: Stages of competence and their significance there is a need to objectively assess ones' skills and training and the need to take rational decisions for patient's benefit. Overestimation of endoscopic ability can lead to complications, which can prove costly for both, the patient and the caregiver. Right planning and appropriate judgment are required before endotherapy. That said, the onus is on the mentors to actively train young endoscopists in acquisition of skill and judgment.

The Swiss cheese model of accident causation also called the cumulative act effect is used in risk analysis and risk management in aviation, engineering, and communication systems. ${ }^{[5]}$ Failure can be usually traced to one of four domains in this model: organizational influences, supervision, preconditions, and specific acts. This system can be largely applied to health care and in particular, to endoscopy services. There is a need for adequate training of endoscopists for skill acquisition and absence of which may be the precondition to accident causation and may lead to specific acts. There is also a need for privileging and credentialing endoscopists for practice and establishing modes for doing the same, which may be deficient due to organizational influences or inadequate supervision. Endoscopy is one of the more rapidly advancing fields of medicine. More number of gastroenterologists wish to learn and practice not only basic diagnostic endoscopy but also advanced interventional endoscopy. However, training opportunities for advanced endoscopic intervention remain few. The development of adequate training opportunities for aspiring endoscopists with collaboration of endoscopic societies and the public

Table 1: The American Society for Gastrointestinal Endoscopy guideline recommendations for privileging and credentialing endoscopy

\begin{tabular}{lc}
\hline Procedure & $\begin{array}{c}\text { Minimum number to } \\
\text { achieve competency }\end{array}$ \\
\hline Upper endoscopy & 130 \\
Colonoscopy & 275 \\
Flexible sigmoidoscopy & 30 \\
ERCP & 200 \\
EUS & 225 \\
Enteral feeding tube placement & 20 \\
Enteral stenting & 10 \\
EMR (upper GI) & 20 \\
ESD (stomach) & 30 \\
\hline
\end{tabular}

$\mathrm{ERCP}=$ Endoscopic retrograde cholangiopancreatography, EUS=Endoscopic ultrasound, EMR=Endoscopic mucosal resection, $\mathrm{ESD}=$ Endoscopic submucosal dissection, $\mathrm{GI}=$ Gastrointestinal 
sector will help boost the availability of endoscopic services across the country. This will also help create a larger pool of proctors for the subsequent generations of endoscopists. Finally, updating any acquired skill is a continuous process and needs appraisal time and again. A system of continuous skill upgradation with objective assessment of the same is required to keep up with various upcoming advances. The need to structure endoscopy training with adequate opportunities for learning is a must, now more than ever.

\section{Sridhar Sundaram}

Department of Gastroenterology, Seth GS Medical College and KEM Hospital, Mumbai, Maharashtra, India

Address for correspondence: Dr. Sridhar Sundaram, Department of Gastroenterology, Seth GS Medical College and KEM Hospital, Mumbai, Maharashtra, India. E-mail: drsridharsundaram@gmail.com

\section{REFERENCES}

1. Kruger J, Dunning D. Unskilled and unaware of it: How difficulties in recognizing one's own incompetence lead to inflated self-assessments. J Pers Soc Psychol 1999;77:1121-34.

2. Dunning D. Self-Insight: Roadblocks and Detours on the Path to
Knowing Thyself. New York: Psychology Press; 2005. p. 14-5.

3. Flower J. In the mush. Physician Exec 1999;25:64-6.

4. ASGE Standards of Practice Committee, Faulx AL, Lightdale JR, Acosta RD, Agrawal D, Bruining DH, et al. Guidelines for privileging, credentialing, and proctoring to perform GI endoscopy. Gastrointest Endosc 2017;85:273-81.

5. Reason J. Human error: Models and management. BMJ 2000;320:768-70

This is an open access journal, and articles are distributed under the terms of the Creative Commons Attribution-NonCommercial-ShareAlike 4.0 License, which allows others to remix, tweak, and build upon the work non-commercially, as long as appropriate credit is given and the new creations are licensed under the identical terms.

\begin{tabular}{|l|l|}
\hline \multicolumn{2}{c|}{ Access this article online } \\
\hline Quick Response Code: & Website: www.jdeonline.in \\
\hline
\end{tabular}

How to cite this article: Sundaram S. Dunning-Kruger effect, stages of competence, and the need for endoscopy training. J Dig Endosc 2018;9:211-2. 